Arteterapia. Papeles de arteterapia y educación para inclusión social ISSN-e 1988-8309

\title{
Hilos y pinturas, llenan de color la vida. Experiencias personales en inclusión
}

\author{
Pilar Lostalé Martínez ${ }^{1}$
}

Recibido: 30 de marzo de 2017 / Aceptado: 21 de julio de 2017

Resumen. Este artículo se basa en mis experiencias vitales relacionadas con el mundo de la costura, y más concretamente de las experiencias como docente ${ }^{2}$ en cursos y talleres que he impartido de costura y labores. De la convivencia y la observación directa con personas mayores sanas o con enfermedades degenerativas, que viven en sus hogares y en residencias geriátricas.

Este artículo pone de manifiesto que la costura y las labores de aguja son actividades ligadas históricamente al género femenino y a su educación, que se usan actualmente como prevención y como terapia en la arteterapia, y finalmente que conceptos como arte, artesanía, bordado y pintura están interrelacionados.

A la vez se defiende que las labores de aguja y las técnicas de costura empleadas están ligadas al patrimonio cultural inmaterial en cada lugar y contribuyen tanto a las prácticas culturales como a la cohesión social del lugar, así como a la inclusión de sus participantes.

Palabras clave: costura y labores de aguja; arte; arteterapia; patrimonio cultural inmaterial.

\section{[en] Threads and paintings, they fill with color the life Personal experiences in inclusion}

\begin{abstract}
This article is based on my vital experiences related to the world of the seam, and more concretely of the experiences as teacher on courses and workshops that I have given of seam and labors. Of the conviviality and the direct observation with major healthy persons or with degenerative diseases, which live in his homes and in geriatric residences.

This article reveals that the seam and the labors of needle are activities tied historically to the female gender and to her education, which are used nowadays as prevention and in the arttherapy as therapy, and finally that concepts like art, crafts, embroidery and painting are interrelated.

At the same time defends itself that the labors of needle and the technologies of seam used are tied to the cultural immaterial heritage in every place and contribute both to the cultural practices and to the social local cohesion, as well as to the incorporation of his participants.
\end{abstract}

Key words: seam and the labors of needle; education; art, arttherapy; heritage.

Sumario. 1. Introducción y objetivos. 2. Costura y labores, patrimonio cultural inmaterial. 3. Evolución de la costura y las labores en nuestro entorno. 4. Arte, bordado y pintura. 5. La costura y las labores en

\footnotetext{
1 Profesora de costura y labores. Graduado Social. Graduada en Relaciones Laborales y Recursos Humanos. Agente de empleo y desarrollo local. Técnica superior en igualdad de género. I Congreso Patrimonio y Creatividad. UVA - Soria

Email: Costuraartesana.alo@gmail.com

2 Cursos y talleres impartidos en Aló! Costura Artesana, adaptados a las necesidades específicas de cada participante.
} 
la arteterapia. 6. Beneficios de las labores. 7. Experiencias personales de los beneficios de las labores. 8. Para reflexionar. 9. Consideraciones finales. 10. Referencias bibliográficas.

Cómo citar: Lostalé Martínez, P. (2017). Hilos y pinturas, llenan de color la vida. Experiencias personales en inclusión, en Arteterapia. Papeles de arteterapia y educación para inclusión social 12, 125-140.

«Necesitamos todas las formas de expresión disponibles y todas las que podamos aprender para entender quiénes somos y qué estamos haciendo aquí.»

Janet H. Murray (1999)

\section{Introducción y objetivos}

Partiendo de mi pasión, desde niña, por el mundo de la artesanía, las labores y especialmente de la costura y la indumentaria, he constatado lo invisibilizadas que están tanto las maestras, académicas o no, en la materia como las costureras y modistas, y la infravaloración a la que están sometidas por parte de un segmento de nuestra sociedad. He experimentado los beneficios de la práctica de la costura, ligados a un estilo de vida saludable, avalados por estudios científicos, que sirven como medio de expresión por igual, tanto a mujeres como hombres, a personas sanas como a personas aquejadas de diversas patologías en sus sesiones de arteterapia. He experimentado, finalmente que en ellas se une la actividad física y mental a un escenario de sociabilidad, de comunicación y educomunicación.

A la vez he constatado, por una parte, que las labores de aguja son motivo de estudio de profesionales de campos tan distintos como el sociosanitario, la educación o el mundo de la moda. Y por otra, que son unas enseñanzas fundamentales para la vida cotidiana. Un día descubrí, gracias a un mi trabajo como agente de empleo y desarrollo rural, que no todas las mujeres mayores sabían coser y que para ellas esta habilidad implicaba tener un mayor nivel cultural y mayor libertad, porque significa que pudieron estar escolarizadas más tiempo que el estrictamente necesario para aprender "las cuatro reglas". Este hecho es algo que se desconoce en la actualidad.

El presente artículo surge de la necesidad de dar a conocer y poner en valor las labores de aguja, desde la educación hasta sus beneficios. Mi objetivo es doble : (i) visibilizar el papel activo que han desempeñado las mujeres como garantes de nuestro patrimonio cultural inmaterial relacionado con la costura, considerado un factor importante en el mantenimiento de la diversidad cultural frente a la creciente globalización, y (ii) visibilizar su actividad docente, así como reconocer su contribución al desarrollo del intelecto. De mujeres anónimas que han tenido una vida común pero una historia interesante

« [...], los objetos de utilidad, tanto cotidiana como excepcional y muchas otras obras suntuarias y decorativas o de simple divertimento pueden ser analizadas desde su específica función social e histórica como desde su sentido lúdico y estético.»

Antonio Bonet Correa (1994) 


\section{Costura y labores, patrimonio cultural inmaterial}

De nuestra pasión por las labores, el reconocimiento y admiración al saber y la educación recibida de nuestras mayores y la poca repercusión que esas mujeres eruditas y las artesanías tienen, en parte de nuestra sociedad y de nuestras instituciones, nos surgen dos necesidades diferentes y complementarias: por una parte la necesidad de dar a conocer a estas mujeres y de poner en valor las labores tradicionales de aguja a través de los talleres de costura que impartimos, y por otra la necesidad de investigar sobre el tema, porque intuimos que su actividad tiene más importancia de la perceptible a simple vista.

Nos encontramos con que estas labores son parte de nuestra cultura y por tanto, están sujetas a diferentes lecturas, por ejemplo desde la antropología física o cultural, la economía preindustrial o industrial, la historia, la sociología, el análisis de género, la teoría de la educación, etcétera. Los puntos de las labores y la manera de hacerlos están considerados parte de nuestro acervo cultural, del patrimonio inmaterial que debemos conservar. La UNESCO hace años que se ocupa de esta cuestión.

La UNESCO, en la Convención celebrada en París en 2003 para la salvaguardia del patrimonio cultural inmaterial, define el patrimonio cultural inmaterial de la siguiente manera:

Artículo 2: Definiciones a los efectos de la presente Convención,

1. Se entiende por "patrimonio cultural inmaterial" los usos, representaciones, expresiones, conocimientos y técnicas -junto con los instrumentos, objetos, artefactos y espacios culturales que les son inherentes- que las comunidades, los grupos y en algunos casos los individuos reconozcan como parte integrante de su patrimonio cultural.

2. El "patrimonio cultural inmaterial" [...] se manifiesta en particular en los ámbitos siguientes: [...]

e) técnicas artesanales tradicionales.

Asimismo, en el texto de la Convención se sostiene que se deberá asegurar el reconocimiento, el respeto y la valorización del patrimonio cultural inmaterial en la sociedad.

La mujer ha desempeñado un papel importante en la transmisión de las tradiciones relacionadas con la costura, fundamentalmente en el ámbito doméstico. También ha contribuido a su permanencia en el tiempo, inculcando estas tradiciones a las generaciones siguientes, en su función educadora desde la infancia. Con los cambios sociales producidos hasta llegar a la coeducación, esto ha ido desapareciendo.

Por todo ello, queremos poner de manifiesto la importancia de la conservación y difusión de esta parte de nuestro patrimonio inmaterial y, en el caso concreto de las labores, visibilizar y valorizar el papel que han desarrollado en la educación femenina, sirviendo como medio para difundir principios y valores en cada época.

El patrimonio cultural inmaterial, como se indica en UNESCO (2015) es tradicional, contemporáneo y viviente a un mismo tiempo, puesto que el patrimonio cultural inmaterial no solo incluye tradiciones heredadas del pasado, sino también usos rurales y urbanos contemporáneos característicos de diversos grupos culturales.

Es integrador porque las personas podemos compartir expresiones del patrimonio cultural inmaterial que son parecidas a las de otros. A modo de ejemplo citaremos 
nuestra experiencia en un taller de personas con discapacidad auditiva, procedentes de lugares diversos. Las labores son un lenguaje universal, estas personas estaban totalmente integradas porque no hace falta oír o hablar para realizar labores en grupo, la satisfacción que sintieron fue enorme porque además de aprender algo útil no se sintieron marginadas como se pueden sentir en otras actividades, que realizan o que dejan de realizar precisamente por sentirse excluidas.

El patrimonio cultural inmaterial está basado en la comunidad porque sólo puede serlo si es reconocido como tal por las comunidades, grupos o individuos que lo crean, mantienen y transmiten. Sin este reconocimiento, nadie puede decidir por ellos que una expresión o un uso determinado forma parte de su patrimonio.

Como afirmaba en 1952 el compositor musical Igor Stravinsky, en su obra Poética musical

una tradición verdadera no es el testimonio de un pasado caduco; es una fuerza viva que anima e informa el presente. Lejos de implicar la repetición de lo que fue, la tradición supone la realidad de lo que perdura. Es como un bien de familia, un patrimonio que se recibe a condición de hacerlo fructificar antes de transmitirlo a los descendientes.

Julio Caro (2011, pg. 243) propugnaba «estudiar al hombre del pasado a la luz de lo que el hombre del presente pueda decirnos». Yo quisiera añadir que hemos de estudiar a la sociedad del pasado a lo luz de lo que las mujeres todavía pueden decirnos, antes de que dejemos de entender los códigos del lenguaje de la costura artesana.

\section{Evolución de la costura y las labores en nuestro entorno}

¿Es casualidad que se encuentre en Japón, país que cuida sus tradiciones sin descuidar la vanguardia, uno de los más grandes museos de la moda occidental de todos los tiempos? ¿o que sea algún sector caduco de nuestra sociedad el que ve la costura y las labores de aguja como algo obsoleto, cuando tal vez son esas personas las que no se han puesto al día de lo que ocurre con las nuevas tendencias?

Las labores en la actualidad están de moda. No obstante, afirmamos no deberían considerarse una moda, pues nos acompañan desde la prehistoria, época de la que datan las primeras agujas de hueso que se conservan.

Si observamos los libros de texto, comprobamos que la Historia ha sido escrita, principalmente por hombres, con su manera de ver la vida, según la cual la importancia reside en el espacio público y lo que allí ocurre, olvidándose de que la historia es la "narración y exposición de los acontecimientos pasados y dignos de memoria, sean públicos o privados". Sin embargo, las mujeres — que durante siglos han vivido en el espacio privado, porque así lo dictaban normas, escritas o no, elaboradas por los hombres, por el rol y las funciones que les fueron encomendadas sociológicamente por su género- han sido las garantes y perpetuadoras tanto de las tradiciones como de la educación, transmitiendo la mayoría de las veces sus conocimientos de forma oral. Aunque las mujeres no hayan escrito la historia también la han vivido. 
Historiadoras e historiadores, deben o deberían preocuparse por dejar constancia escrita de una actividad a la que las mujeres han dedicado muchas horas de su vida, que les ha aportado la posibilidad de dar sentido a su vida, la costura, en ocasiones, era el único medio que tenían para poder expresar su creatividad.

Desde la prehistoria, la mujer se ha dedicado al cuidado y la educación de la prole. Si damos un salto hasta el siglo XIX, cuando surgen las primeras escuelas públicas, con un enfoque antropocéntrico, vemos cómo se relaciona las labores de aguja con la instrucción para las niñas. Desde que en España se estableció la obligatoriedad de dicha instrucción (en 1857 con la ley Moyano) hasta el último tercio del siglo XX (cuando en 1970 la Ley General de Educación declara totalmente derogada su obligatoriedad), las leyes marcaban que en las enseñanzas de las niñas se omitirían las asignaturas de Agricultura, Industria y Comercio, reemplazándolas por asignaturas como Labores propias del sexo, Dibujo aplicado a las mismas labores, Geometría, Ligeras nociones de higiene doméstica, Guía de la buena madre o Economía doméstica.

Si reflexionamos un poco, podemos afirmar que las niñas estaban discriminadas en su educación. Tampoco debemos olvidar a los niños, discriminados igualmente ya que no tenían acceso a las materias consideradas en la educación de las niñas exclusivamente. Hubo niños que se sintieron excluidos de unas enseñanzas tan útiles para la vida diaria de ambos sexos.

Pero también es cierto que no podemos extrapolar esa afirmación a un pasado remoto, donde las tareas privadas eran consideradas de igual importancia que las tareas públicas y por eso pervivieron durante tantos años a lo largo del tiempo, donde era el instinto de supervivencia lo que llevaba a mujeres y hombres a repartirse las tareas cotidianas, como lo hacemos hoy cuando trabajamos en equipo, en colaboración.

\section{Arte, bordado y pintura}

Según indica el diccionario de la RAE (2014), arte es la capacidad, habilidad para hacer algo. También que es la manifestación de la actividad humana mediante la cual se interpreta lo real o se plasma lo imaginario con recursos plásticos, lingüísticos o sonoros.

Así como bellas artes, lo define como el conjunto de las que tienen por objeto expresar la belleza, y especialmente la pintura, la escultura y la música.

Como indica Marián López F. Cao $(2011,33)$

el arte con mayúsculas se ha preocupado en reforzar la individualidad como característica de la práctica artística, [y] de establecer claramente jerarquías, para hacer sobresalir a un individuo por encima del grupo, para señalar maestro y seguidores, maestro y discípulos. [... Aunque] las creaciones artísticas realizadas en cooperación, como la artesanía y el arte popular, «arte intrínsecamente solidario», relacionados con el grupo, muchas veces han dado resultados más enriquecedores.

El arte como otras disciplinas académicas se puede enseñar, porque se puede desarrollar o perfeccionar las aptitudes y capacidades del alumno/aprendiz. Y como 
toda manifestación educativa — según los Objetivos estratégicos de la ET2020³ - la enseñanza del arte ha de ser inclusiva, y se basará en la igualdad, la equidad, la no discriminación y la promoción de las competencias cívicas.

Sin embargo, y pese a estas declaraciones de intenciones y lo expuesto anteriormente, el arte producido por las mujeres, ya sea erudito o popular, se invisibiliza en nuestra sociedad. Quizá una razón que explique esta invisibilidad resida en el hecho de que las mujeres realizan sus labores de aguja en el espacio doméstico, solas o en grupo, siempre como parte de sus labores cotidianas.

Pintar, según el diccionario de la RAE significa «representar algo en una superficie con líneas y colores» y «cubrir con un color la superficie de algo». Cuando escuchamos esta definiciones, ¿qué imagen nos formamos en nuestra mente?, ¿Cuántas veces será un cuadro pintado? ¿Y cuántas un cuadro bordado?

Tomemos dos ejemplos de bordados que encajan en la definición anterior. El primero data de finales del siglo XVI, (v. figura 1). Se trata de un vestido bordado compuesto de dos piezas. El segundo pertenece a la actualidad y es obra de Cayce Zavaglia $^{4}$ (v. figura. 2).

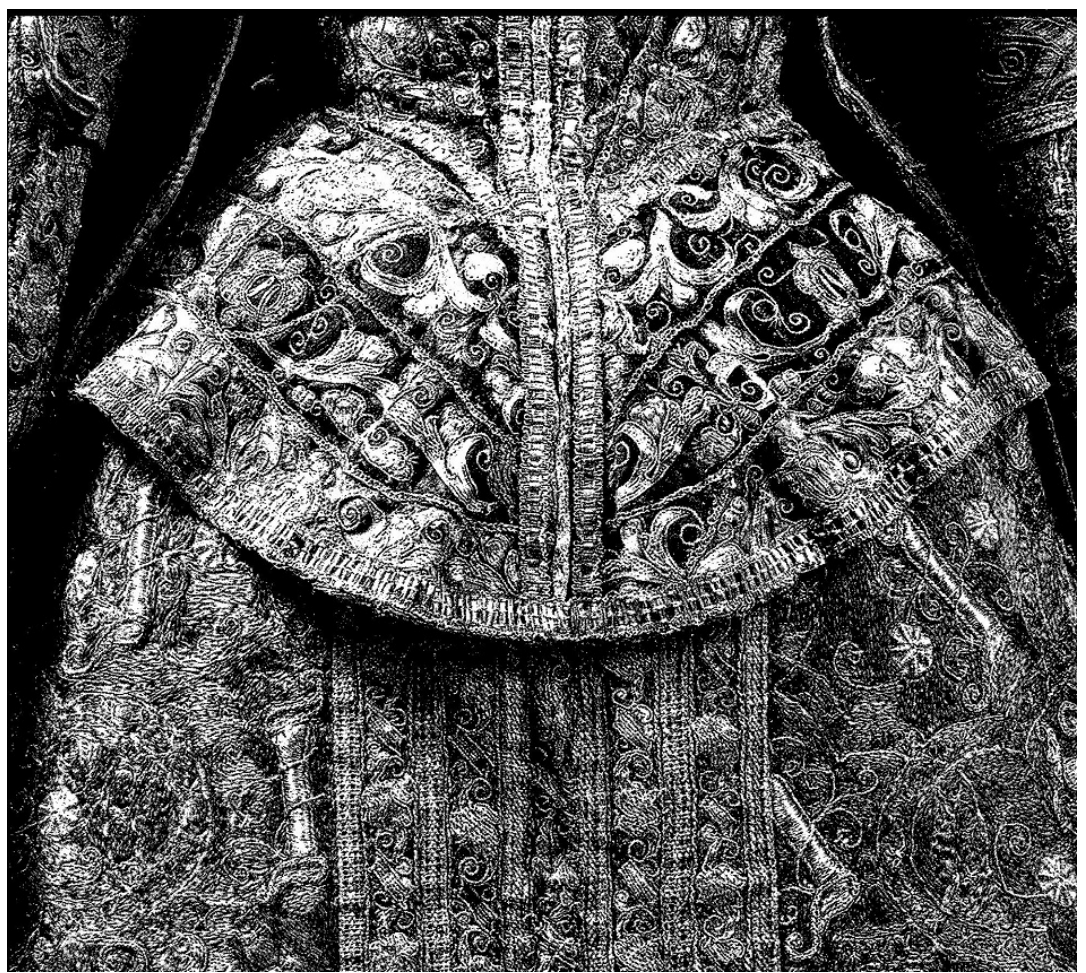

Fig. 1 Vestido bordado compuesto de dos piezas. Siglo XVI

Fuente: Estudios sobre indumentaria española en la época de los Austrias. (2014) Miguel Herrero García

ET 2020 es el Marco Estratégico de Educación y Formación 2020 conocido por sus siglas en inglés ET Education and Training)

4 Cayce Zavaglia: artista, pintora y original bordadora, nacida en Luisiana y criada en Australia. 


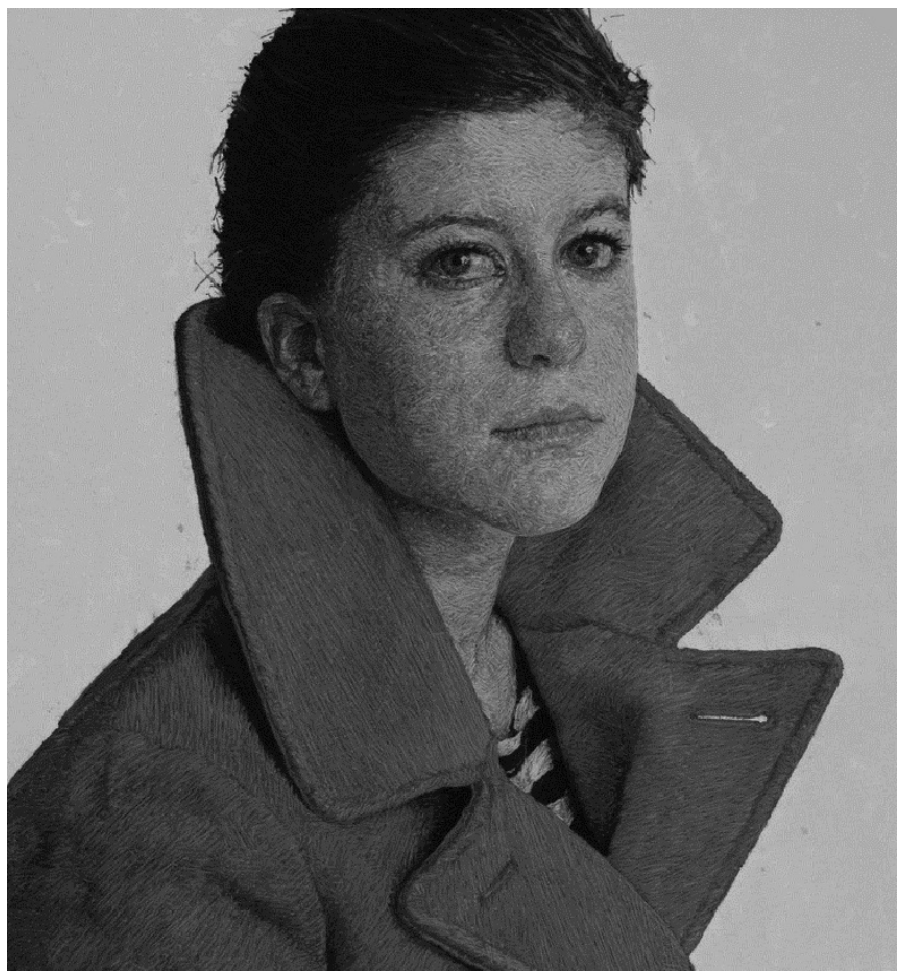

Fig. 2 Cuadro bordado. Actualidad

Autora: Cayce Zavaglia. Fuente: http://www.caycezavaglia.com/details

Viendo las imágenes anteriores, podemos concluir que las labores de bordado encajan efectivamente en las definiciones de pintar y de arte; tanto en la actualidad y en épocas recientes, cuando los bordados son considerados "labores de mujeres", como en el pasado, cuando los bordados eran tan apreciados y valorados como los manuscritos iluminados, [...], la escultura o la pintura mural como indica Kay Staniland (2000).

Como apunta $\mathrm{M}^{\mathrm{a}}$ Ángeles González Mena en Antonio Bonet Correa $(1994,389)$ «en España el bordado constituye una de las artes más antiguas», independientemente de si las manos que lo realizan son femeninas o masculinas.

Y Concha Herranz Rodríguez, (2011) mantiene que la mujer « ha alcanzado la perfección y ha producido piezas de calidad extraordinaria, [...] de manera que desde antiguo las prendas y piezas bordadas han representado parte del patrimonio familiar»

Existen muchos ejemplos de bordados, tapices y demás objetos realizados con hilo y aguja que se exponen en los museos, no sólo etnográficos o de indumentaria específicamente.

Como se puede comprobar el bordado, como arte y como elemento de adorno en la indumentaria nos acompaña desde la prehistoria hasta nuestros días. Sirvan a modo de ejemplo:

Concha Herranz Rodríguez es conservadora del Museo del Traje. 
- como indica Kay Staniland (2000) un hallazgo arqueológico procedente de los enterramientos de Skrydstrup (Dinamarca), el bordado más antiguo del que tenemos constancia en Europa, datado en la Edad de Bronce (1500-500 a.C.).

- como señala Marián López $(2011,61)$, en el Museo de Arte e industria de Viena, se expone un bordado, obra del S. XIII, atribuido a Kunigunda.

- O los vestidos, bordados a mano, de la última colección 2017 de las casas de alta costura.

\section{La costura y las labores en la arteterapia}

La arteterapia, la arte terapia o psicoterapia por el arte, como lo definen Diana Arias y Claudia Vargas (2003), es una forma de terapia psicológica que pone el acento en el arte y la creatividad del individuo, y no en el lenguaje hablado. Utilizan las prácticas artísticas para tratar a los pacientes. Y Marián López define (2006) la arteterapia como «el conocimiento interior a través de la expresión artística, un excelente instrumento que permite sentir la voz que sale del interior del ser humano, con todo lo que el subconsciente guarda».

En definitiva lo que se quiere conseguir por medio de la arteterapia, es calidad de vida, una vida saludable, para los pacientes.

Como indica el diccionario de la RAE, costura procede «del latín vulgar * consutūra arte de coser». Sus dos primeras acepciones son «acción y efecto de coser»y «labor que está cosiéndose y se halla sin acabar».

Aunque las definiciones han ido cambiando a lo largo del tiempo, en las definiciones de las artes mayores, nos encontramos con que pintura es el arte de pintar, literatura el arte de la expresión verbal, escultura el arte de modelar y arquitectura el arte de proyectar y construir edificios. ¿En qué momento de la historia se relegó a la costura de su primigenia definición, que perdura en las demás artes?

Si el lenguaje expresa con palabras lo que pensamos y sentimos, la costura, que cuando se usaba el latín como lengua vehicular, era el "arte de coser" - en el castellano moderno se queda en la acción y efecto de «unir con hilo, generalmente enhebrado en la aguja, dos o más pedazos de tela, cuero u otra materia o en «hacer o reparar una prenda, especialmente ropa de vestir, con aguja o a máquina». ¿Ya no percibimos que la costura es arte o no lo perciben los académicos de la lengua?

En los libros y manuales de arteterapia, que he consultado para este trabajo, he apreciado que se describe cómo se utilizan las técnicas de: pintura, escultura, cerámica, escritura, música, baile, teatro, manualidades, cocina. Pero en ninguno queda reflejado el arte de la costura, del bordado, de las labores en general.

Tampoco tiene espacio este arte en las asignaturas de los estudios reglados de arteterapia.

Si esto es así, se está disociando a las personas interesadas en la arteterapia-estudiantes, docentes y profesionales - de un gran grupo de potenciales pacientes, tanto hombres como mujeres, al no estar contemplados los intereses y conocimientos previos del público cuyos problemas (enfermedad) se está tratando de resolver.

Sin embargo, la realidad es que las labores - así está documentado- se utilizan en arteterapia desde el s. XV. El hospital de los Inocentes de Valencia fue pionero en utilizar esta disciplina con enfermos mentales, porque se pueden realizar proyectos 
cuyos resultados se ven a corto plazo. De este modo es más fácil mantener la atención y concentración que cuando la terminación de un proyecto es a más largo plazo, como por ejemplo un cuadro pintado al óleo. Además de que es un aprendizaje útil para la vida diaria, lo que le da más valor en este tipo de pacientes.

En la actualidad se continúan utilizando tanto para enfermos mentales como pacientes con diferentes enfermedades motoras o sensoriales. Y se ha puesto de manifiesto que muchas mujeres mayores encuentran su rehabilitación a través de sus conocimientos previos de costura, aunque no sean capaces de aprender una técnica nueva como la pintura.

Por todo lo expuesto en los párrafos precedentes, y debido a que el uso de la costura y el bordado está generalizado en el trabajo diario y la práctica de los arteterapeutas, entiendo que se debería considerar la inclusión de la costura y el bordado en la guía docente de los estudios de arteterapia.

\section{Beneficios de las labores ${ }^{6}$}

Las labores favorecen y facilitan el aprendizaje a lo largo de la vida, y la transferencia de conocimientos, académicos o no, fomentando la creatividad. El psicólogo e investigador Howard Gardner ${ }^{7}$, mantiene en su reconocida teoría de las inteligencias múltiples que "no existe una inteligencia única en el ser humano, sino una diversidad de inteligencias", que trabajan juntas, aunque como entidades semiautónomas. Entre ellas cita la "inteligencia corporal y cinética", que es la facilidad para procesar el conocimiento a través de las sensaciones corporales como el deporte, baile o la costura.

Aunque han desaparecido del currículo de las enseñanzas básicas obligatorias, las labores continúan presentes en las enseñanzas obligatorias, en centros escolares con metodologías "novedosas y originales" basadas en el pasado, adaptadas al tiempo actual, no obligatorias y superiores, incluso en la educación de adultos.

Las labores son una manera de que las personas adquieran y amplíen sus conocimientos y habilidades para su desarrollo personal o laboral, para su inclusión social. Porque las labores de aguja ayudan tanto a la integración social como a la inclusión laboral.

Las labores sirven para mantener vivo parte de nuestro patrimonio cultural. Si solo se conserva el objeto (pensemos en una indumentaria conservada en un museo), los secretos de su elaboración morirán junto con sus últimos practicantes.

Las labores son una actividad integradora y socializadora, de la que puede beneficiarse toda la sociedad. Se pueden realizar actividades destinadas a cada grupo de edad o a grupos intergeneracionales y a personas con diferentes niveles de necesidades por cubrir.

Tomando como referencia la teoría de la motivación de Abrahan Maslow, se pueden analizar los beneficios de las labores, donde, como indican Diana Arias y Claudia Vargas (2003), la autorrealización ocupa un lugar muy destacado en la jerarquía de las necesidades. Las necesidades que según el psicólogo Maslow pueden ordenarse jerárquicamente en cinco niveles, según vemos a continuación:

Experiencias de autoempleo innovadoras para el desarrollo local

Howard Gardner: profesor de la universidad de Harvard y Premio Príncipe de Asturias 2011. 
- En primer lugar en el nivel más inferior y elemental, se encuentra la necesidad fisiológica básica de vestido, que sirve tanto al abrigo como al objetivo de ser vistos por los demás de una forma agradable. Las personas pueden adquirir conocimientos para realizar sus propias prendas de vestir y con creatividad adaptarlas a la moda, a sus propios gustos o sus necesidades y la de sus allegados.

- En segundo lugar se encuentra la necesidad de seguridad, que podría estar cubierta con un trabajo digno. Con lo aprendido en los talleres de labores dirigidos a personas en riesgo de exclusión, éstas adquieren habilidades y destrezas que pueden ayudarles a conseguir un trabajo digno. Existe una amplia gama de trabajos relacionados con la costura y las labores de aguja.

- En tercer lugar se sitúa la necesidad de filiación, de pertenencia a un grupo. Cuando una actividad se realiza en equipo es más gratificante que cuando se realiza en solitario. Las actividades de costura, a través del tiempo se han realizado y se continúan realizando en grupo, ya estén destinadas a niños, adultos o ya sean de carácter intergeneracional, con lo que hay ocasión de relacionarse con otras personas. Normalmente las personas de más edad son estimadas por su sabiduría y experiencia por las personas más jóvenes del grupo. Y estas, a su vez, aportan vitalidad a las personas mayores.

- En cuarto lugar, encontramos la necesidad del reconocimiento externo, la confianza, la autoestima. Estas pueden venir a través de diversas fuentes, de una manera explícita o implícita, por ejemplo con la orgullosa exhibición de nuestros avances y logros, en una exposición colectiva de nuestros proyectos terminados o subiendo a las redes sociales fotografías de los mismos, si las actividades son noticia en los periódicos, o si se recibe el reconocimiento al trabajo de otros miembros del grupo o una opinión positiva de personas que admiran los trabajos.

- Y por último, cuando se tienen todas las demás necesidades vitales cubiertas, en el nivel más alto de la pirámide está la autorrealización, la motivación interna y trascendente. Quien realiza una labor por puro placer, es feliz. Las personas se sienten satisfechas y plenamente realizadas por haber logrado cumplir aquello a lo que aspiraban.

Las labores y sus beneficios van dirigidas a:

- personas mayores, que teniendo todas sus necesidades vitales cubiertas y satisfechas, precisan de una labor manual y artística con la que sentirse autorrealizadas.

- personas de cualquier edad y, especialmente el público infantil, que consiguen el reconocimiento externo y la autoconfianza, así como sentirse apreciados, estimados y reconocidos cultivando el arte de las labores de aguja.

- personas, de todas las edades, que tienen las mismas aficiones y necesitan el apoyo de un grupo para sentirse realizadas.

- personas que no tienen afición a las labores pero que necesitan aprender las nociones básicas y que desarrollando sus capacidades y aptitudes, se sienten motivados.

- personas en riesgo de exclusión, que poniendo en práctica destrezas y herramientas adecuadas aprendidas con las actividades, poniéndolas en práctica pueden entrar en el mercado laboral. 
En general, podemos decir que las labores son un hábito de vida saludable y sirven como terapia. Los beneficios de las labores ayudan a:

- desarrollar la destreza manual, la psicomotricidad fina;

- desarrollar la coordinación;

- desarrollar la Inteligencia visual-espacial, la coordinación óculo-manual;

- desarrollar el área cognitiva a través de las labores;

- desarrollar la capacidad de concentración, atención y relajación;

- estimular la creatividad;

- expresar la creatividad y el arte con la aguja:

- aprender a trabajar en equipo;

- despertar el interés por el medioambiente y el reciclaje;

- conseguir que las personas sean autosuficientes en actividades instrumentales en la vida diaria:

- crear interés por las cosas hechas a mano, por las prendas únicas y con la huella de la persona que las elabora;

- crear un espacio único para compartir conocimientos, disfrutar de las pequeñas cosas y tomar el control del propio tiempo;

- apreciar lo local, la manera de hacer de aquí y también lo global, participar de otras culturas y otra forma de hacer;

- valorar las labores tradicionales, reinventándolas para la moda actual;

- conservar el medioambiente, a través de la sensibilización de la cultura de las tres erres (reducir, reutilizar y reciclar);

- valorar el tiempo y la destreza que requiere lo hecho a mano, por uno mismo o por otras personas.

\section{Experiencias personales de los beneficios de las labores}

Sobre los beneficios de las labores existen numerosos estudios y artículos científicos. Este artículo, no obstante, no está basado exclusivamente en estudios teóricos sino que partiendo de ellos, expongo mis propias conclusiones, con un enfoque cualitativo, con base en mi propia experiencia personal, adquirida en las actividades ofrecidas. Todos los beneficios contemplados en este artículo, son parte de la experiencia de las personas que han participado en nuestros talleres, de las actividades que hemos organizado e impartido.

Son experiencias recogidas en los diferentes lugares en los que hemos trabajado: desde la universidad hasta la terraza de un bar, o un espacio de coworking, pasando por institutos o asociaciones tan diferentes como de personas con discapacidad auditiva, de vecinos o de mujeres empresarias, e incluso en un museo de arte contemporáneo.

En los diferentes talleres, todos ellos inclusivos, desde costura elemental y de supervivencia hasta de patronaje y confección. Hemos tenido la suerte de contar con participantes muy diversos en edad y condición: 
- con edades comprendidas entre los tres y los noventa y seis años.

- con personas sanas, vitales y con personas con enfermedades físicas, mentales, neurológicas, motoras, degenerativas, etcétera.

- con personas con capacidades diferentes y con diferentes capacidades.

- con personas muy habilidosas y con personas que suplían con mucho interés su falta de habilidad.

- con personas muy exigentes y perfeccionistas a las que teníamos que hacer ver que en el aprendizaje el proceso es tan importante como el resultado y con personas que con hacer una puntada derecha se conformaban y a las que alentar para que mejoraran su trabajo.

- siempre hemos puesto un número orientativo de participantes, pero en alguna ocasión hemos tenido talleres de más de veinte personas y talleres unipersonales.

- personas con estudios universitarios y personas con pocos estudios, incluso sin concluir los estudios básicos, pero con gran sabiduría.

- con personas de los cinco continentes, de países tan diversos como España, Polonia, Rusia, Japón, Brasil, República Dominicana, Estados Unidos, Marruecos o Australia.

- personas sin conocimientos previos, que literalmente no sabían coser un botón y personas que tenían una larga trayectoria en este mundo pero querían trabajar en grupo. O que tenían estudios de diseño de moda en prestigiosas escuelas de Londres o Nueva York y conocimientos técnicos en inglés pero desconocían el vocabulario en español.

- personas aficionadas desde siempre a la costura y personas que se han apuntado a un taller por pura necesidad, porque habían desaparecido las personas cercanas que les realizaban esas labores y se han aficionado con nosotras y continúan confeccionando sus propias prendas originales y únicas.

- personas jóvenes alegres y vitales, y personas que encuentran en la costura y en el grupo un espacio de convivencia, de relación con los demás, una vía de escape para su soledad y aislamiento en el que viven cuando, por unas razones u otras, se quedan solas.

\section{Para reflexionar}

- ¿El arte deja de ser arte por ser anónimo?

- El arte ¿es arte mayor o menor dependiendo de si está hecho por una persona, por varias o por toda una comunidad?

- El bordado, en algunas épocas pasadas, tuvo tanta importancia como la pintura y si es verdad que los maestros bordadores eran hombres, no es menos cierto que las manos de mujeres bordaron obras de gran valor, aunque no fueran reconocidas socialmente, como demuestra Kay Staniland (2000) en su libro «Artesanos Medievales Bordadores».

- Si en la actualidad, de la costura como actividad laboral, se ocuparan principalmente los hombres ¿Tendría la misma, más o menos importancia y relevancia que al ser considerada "una tarea de mujeres"? 
- ¿Realmente la costura y las labores son sólo y exclusivamente "una tarea de mujeres"?, En la introducción se apuntaba que no todas las mujeres saben coser, algunas ni enhebrar una aguja. Sin embargo hay hombres que por su trabajo o sus aficiones tienen relación, de una manera u otra, con la costura.

- Como he indicado anteriormente, de los libros de arteterapia que he consultado, en ninguno de ellos aparecen las labores de aguja como terapia. En cambio sí aparecen la pintura, cerámica, dibujo, etc. Sin embargo la primera terapia de la que tenemos constancia, como hemos comentado en el apartado de "La costura y las labores en la arteterapia", en el S.XV fue la costura, utilizada en el hospital de los Inocentes de Valencia. Así que no es una novedad.

- Cuando la enseñanza estaba segregada por sexos, la mujer aprendió con las labores a escribir. Quizás fue poco, pero, de esta manera tuvo acceso a la cultura, a la educación reglada. Si tan importante se ha demostrado que son las labores para las conexiones neuronales ¿por qué no se continúa enseñando por igual a niños y niñas? ¿Y si en el pasado hubiera sido materia de estudio de los niños, ¿estaríamos en la misma situación?

- Aunque las labores fueron cosa de mujeres, pienso que deberíamos dar el valor que merecen, las labores son parte de nuestro acervo cultural y como tal deben ser tratadas.

- Pensemos en la relación que tiene la mano y el cerebro en cualquier actividad manual, en cualquier oficio artesano, mi profesor de dibujo nos recalcaba "Que no dibuja la mano, que dibuja el cerebro», de la misma manera podemos decir que cuando bordamos, no borda la mano, que borda el cerebro, Tawil ${ }^{8}$ (2015) y Sennett (2009) nos indican que existe una estrecha interdependencia entre bienestar físico e intelectual, así como una interconexión entre cerebro emocional y cognitivo, cerebro analítico y creativo, cómo la mano y el ojo trabajan conjuntamente para adquirir la destreza necesaria en una tarea manual, artesana, y el lugar que ocupa en el cerebro.

Lo que no está escrito no existe. Hagamos lo que esté en nuestras manos para que esto cambie. Porque una cosa es que no entendamos el lenguaje de las labores y otra cosa muy distinta que las piezas de ajuar, vestiduras, tapices y demás no sean arte con mayúsculas. Cuando un ignorante en la materia desprecia el arte, no por eso deja de ser arte, habrá que educar al individuo para que lo entienda, no para que lo ignore.

En una noche cerrada de verano, en las fiestas de un pueblo, los fuegos artificiales estallan. Un niño que aún no ha cumplido seis años grita, para hacerse oír entre el estruendo: «¡Mira mamá, un ocho!» y su hermano, que acaba de cumplir dos, responde: «iNo, es una flor!»

Dos maneras diferentes de ver y sentir un mismo hecho, ¿Cuál es la interpretación más real?

Si dos hermanos de la misma familia son diferentes y aprenden a ver la realidad según sus propias experiencias, mucho más lo serán los pacientes de arteterapia, que vienen de situaciones y educaciones diferentes. La arteterapia debería ser inclusiva, con todas las historias personales de sus pacientes. Una persona por estar enferma, no deja de ser ella misma y sus circunstancias.

Sobhi Tawil es el especialista principal del programa EPT (Educación Para Todos) y la agenda mundial de la UNESCO 
Es un hecho que en España, todas las mujeres de más de cincuenta años y algunas de menos han aprendido labores en la escuela, ¿Cuántas de ellas han invertido tantas horas en aprender a pintar, a esculpir, u otras artes?

Para algunas de ellas, la costura será una tortura por diversas circunstancias que no vamos a tratar aquí. Para la inmensa mayoría será parte de su vida, les habrá servido para vivir otros mundos, otras vidas, en su imaginación.

\section{Consideraciones finales}

Debemos pensar que gran parte de la población tienen unos conocimientos básicos en la materia, que no tienen por qué tener en otras disciplinas artísticas. Porque las «labores propias de su sexo» fueron materia obligatoria en el currículo de las niñas desde mediados del siglo XIX hasta el último tercio del pasado siglo; y después continuaron como materia optativa en el currículo de escuelas e institutos, e incluso hoy en día estas labores forman parte de proyectos novedosos, de aprendizaje mediante la metodología de grupos interactivos en la coeducación, de niñas y niños.

Si una persona enferma tiene dificultad para aprender cosas nuevas, potenciemos las labores, aprendidas y guardadas en la "retina" para potenciar otros aprendizajes, terapias y recuperación del bienestar físico y mental.

Porque partiendo desde un arte inclusivo, ¿cuántas personas dejan de estar incluidas cuando acuden a sesiones de arteterapia? Sabemos seguro que se les ha enseñado a coser, no tenemos la certeza, por ejemplo, de que sepan pintar. Sin embargo si un día asisten como pacientes a arteterapia, ¿les dejarán expresarse como saben?, ¿como han aprendido? o ¿el terapeuta, «ajeno a la experiencia de los educandos» les guiará o incluso les impondrá que se expresen en un lenguaje desconocido para ellas?

Como cita Marián López F. Cao $(2011,17)$

Monserrat Moreno recordaba cómo la historia transmitida, cerrada y compartimentalizada, ajena a la experiencia de los educandos, relataba la historia del poder, [...] silenciando, olvidando y tachando a las clases populares, a la sociedad civil y por supuesto a las mujeres.

Escuchando las palabras de personas cuidadoras y trabajadoras con personas mayores, especialmente una con más de 30 años de experiencia en el sector, me dijo que no olvidara que algunas mujeres mayores no saben coser.

Soy consciente de que no todas las mujeres de cierta edad saben coser, pero mi finalidad es que se tenga en cuenta a tantas mujeres que han dedicado más de diez mil horas de su vida a la costura, el tiempo considerado normal para convertirse en experto según Richard Sennett (2009) «representa el tiempo que los investigadores estiman necesario para que habilidades complejas se arraiguen con profundidad suficiente para utilizarlas sin esfuerzo, para convertirse en conocimiento tácito». Y por sus circunstancias físicas, mentales o motoras, no son capaces de adquirir nuevos conocimientos y habilidades complejas, pero sí de continuar practicando habilidades que tienen interiorizadas. Que a cada persona le hagan partícipe de actividades que sepan realizar o de actividades que supongan un reto alcanzable. 
La costura tiene su lenguaje no verbal, que es inclusivo porque en una misma actividad pueden participar personas de distintas nacionalidades, con diferentes idiomas, incluso personas que no manejan el lenguaje verbal, como las personas con discapacidad auditiva. Porque las labores de aguja se pueden explicar mediante gráficos y las personas participantes pueden seguir perfectamente una clase, incluso sin hablar.

Aprovechemos su recurso, su valor intangible, utilicemos su potencial inclusivo con las personas usuarias. Entiendo que los terapeutas, hombres y mujeres, con más recursos, son los que se deben adaptar a los usuarios/pacientes y no al revés. Para ello deberían tener en cuenta los medios expresivos aprendidos por estos últimos, deberían aprenderlos para después poder ponerlos en práctica en su trabajo.

Las labores de aguja nos acompañan desde la prehistoria. En unos momentos u otros de la historia, han sido mejor o peor consideradas según la época. Es una realidad que en la actualidad interesa tanto a personas mayores como a personas jóvenes de ambos sexos y más en lugares donde la sociedad es más abierta y plural.

Buscando un símil, la rueda es un invento que se remonta a la prehistoria, pero hoy nos sigue siendo útil porque hemos adaptado sus usos a nuestras necesidades, por lo que no la desechamos por antigua u obsoleta. De la misma manera, las labores, nos siguen siendo útiles, a la vez que pueden ser muy creativas. La innovación puede estar en el proceso, en la manera de enseñarlas. No debemos despreciarlas por desconocimiento o por no saber adaptarlas a las necesidades actuales.

La identidad, el sentido de pertenencia, hoy como ayer, es una necesidad del ser humano, en los meses de mayo y junio de 2016 pude comprobarlo a través de la exposición que organicé: "Cosiendo nuestra historia. Aprender y preservar un valioso patrimonio inmaterial". En ella mostraba un recorrido por aspectos sociales, didácticos y culturales que las labores de aguja han tenido en nuestro entorno en los dos últimos siglos.

Como a priori se puede suponer, la exposición interesó a personas mayores, tanto maestras, como modistas, costureras y mujeres en general, que un día aprendieron de sus mayores y que a su vez ellas también enseñaron. Pero en igual medida interesó, y esto puede sorprender más por desconocimiento, a hombres que aprendieron de niños, a quienes los conocimientos adquiridos en la materia, les has servido a lo largo de su vida; entre ellos se hallaban desde pastores hasta cirujanos, sin olvidarnos de diseñadores o pintores. A jóvenes estudiantes de traducción e interpretación —que vieron cómo una salida profesional puede ser traducir libros de labores a otros idiomas-, incluso al público infantil, creativos por naturaleza, que ven un mundo lleno de color y posibilidades en los hilos y los tejidos.

En ese tiempo pude comprobar que las labores son reconocidas por todos como algo nuestro, que muy diferentes colectivos, tenemos un interés común: la costura. Cada persona tenía una historia que contar, una experiencia vivida en torno a ellas. Son pocas, por no decir ninguna, las personas que no se reconocían en algún objeto, en algún libro. Por ello podemos decir que la costura y las labores están en la memoria colectiva de todos, y que a todos nos corresponde preservar tanto la parte material como inmaterial que representan. También al colectivo de arteterapeutas.

Cuando se diseñe una guía docente de arteterapia deberían incluirse las labores, porque son un medio de expresión del arte, de la creatividad que todas las personas llevamos dentro, como lo puede ser la pintura, la fotografía, la música u otras disciplinas ya contempladas. 


\section{Referencias bibliográficas y webgráficas}

Arias, D y Vargas, C (2003) La creación artística como terapia, Barcelona, rba libros.

Bonet Correa, A (1994) Historia de las artes aplicadas e industriales en España, Madrid, ediciones cátedra.

Caro, J. (2011) Análisis de la cultura. Etnología, historia, folklore. Ministerio de Cultura. Molina de Segura (Murcia)

Eisner, W. (2012). Educar la visión artística. Barcelona: Paidós Educador.

Herranz Rodriguez, C. (2011), Mujeres bordadoras: Patrimonio en femenino (pp. 34-35). Madrid, Ministerio de Cultura.

Ibarrola, M. http://alocosturaartesana.wordpress.com/

López F. Cao y Martínez Díez, N (2006), Arteterapia, Madrid, tutor.

López F. Cao, M. (2011), Mulier me fecit. Hacia un análisis feminista del arte y su educación, Madrid, horas y Horas.

Lostalé, P (2015) Trabajo Fin de Grado Experiencias de autoempleo innovadoras para el desarrollo local, Soria, Facultad de ciencias empresariales y del trabajo.

Murray, J. (1999): Hamlet en la holocubierta. El futuro de la narrativa en el ciberespacio. Barcelona, Paidós

Sennett, R (2009), El artesano, Barcelona, editorial Anagrama

Staniland, K (2000), Artesanos Medievales. Bordadores, Madrid, ediciones Akal

Real Academia Española, Diccionario de la lengua española (2014), Mardid, Espasa, Consulta en red en http://www.rae.es

Tawil y otros (2015) Replantear la educación ¿Hacia un bien común mundial? Paris: UNESCO.

UNESCO. (2015). Documento de posición sobre la educación después de 2015 ¿Qué es el patrimonio cultural inmaterial? Consulta en red en http://www.unesco.org/culture/ich/es/ que-es-el-patrimonio-inmaterial-00003 